\title{
Spatial resolution of scanning tunneling microscopy
}

\author{
T.Rozouvan, L.Poperenko, I.Shaykevich, S.Rozouvan \\ Faculty of Physics, T. Shevchenko National University of Kyiv, \\ 2 Glushkova Ave., 03680 Kyiv, Ukraine
}

\section{Received April 4, 2015}

\begin{abstract}
Time-independent Schroedinger equation solution in paraxial approximation is obtained for de Broglie wave of electron. The solution results in exact ratios for spatial resolution of scanning tunneling microscopy (STM) of nanoobjects on a metal substrate. STM experiments on semiconductor and metal carbon nanotubes were performed in order to check the theoretical approach. The spatial resolution of the experiments reached $0.06 \mathrm{~nm}$. Hexagonal structure on the semiconductor nanotube surface was registered. Relatively lower spatial resolution for the metal carbon nanotubes which is also different along and across nanotubes was registered and explained in frames of the proposed theoretical modeling. A basic ratio for STM spatial resolution for the arbitrary nanoobject was derived as a result of the approach.
\end{abstract}

Keywords: scanning tunneling microscopy, carbon nanotubes, Schroedinger equation

Решение стационарного уравнения Шредингера в параксиальном приближении получено для де-Бройлевской волны электрона. Соотношение позволяет получить точное решение для пространственного разрешения сканирующей туннельной микроскопии (CTM) при измерении нанообъектов на металлической поверхности. Проведены СТМ эксперименты с металлическими и полупроводниковыми углеродными нанотрубками для подтверждения теоретической модели. Пространственное разрешение при измерениях достигало 0.06 нм. Измерена гексагональная структура поверхности полупроводниковой нанотрубки. Получено сравнительно более низкое пространственное разрешение для металлической углеродной нанотрубки различающееся в направлениях вдоль и поперек нанотрубки. Эффект был обьяснен в рамках теоретической модели. Как результат данного теоретического подхода было выведено базисное соотношение пространственного разрешения СТМ для произвольного нанообъекта.

Просторова роздільна здатність скануючої тунельної мікроскопії. Т.Розуван, Л.Поперенко, И.Шайкевич, С.Розуван.

Рішення стаціонарного рівняння Шредінгера у параксіальному наближенні отримано для де-Бройлівської хвилі електрону. Співвідношення дозволяє отримувати точне рішення для просторового розподілу скануючої тунельної мікроскопії (СTM) при вимірах нанооб'єктів на металевій поверхні. Проведено СТМ експерименти с металевими та напівпровідниковими вуглецевими нанотрубками для підтверждення теоретичної моделі. Просторова роздільна здатність при вимірах досягала 0.06 нм. Виміряно гексагональну структуру поверхні напівпровідникової нанотрубки. Отримано порівняно більш низьку просторову роздільну здатність для металевої вуглецевої нанотрубки, яка розрізнялась у повздовжному та поперечному напрямках. Ефект пояснено у рамках теоретичної моделі. Як результат даного теоретичного підходу отримано базисне співвідношення просторового розподілу СТМ для довільного нанооб'екту. 


\section{Introduction}

Discovery of carbon nanotubes, the cylindrical carbon molecules with outstanding mechanical and transport properties, has been considered of great interest and value by scientific communities worldwide. Carbon nanotubes possess unique properties which make them the ultimate carbon fiber and make them arguably the most irreplaceable basic building element for nanodevices. During the making of nanodevice for the contact to nanotube (e.g. by depositing it on a metal substrate) the key moment is the physical processes which happen in the thin nanotube-substrate interface layer which includes the electrical current in semiconductor and metal nanotubes. The formation of Schottky or p-n semiconductors junctions buildup on the nanotubes basis serve as an example of the complexity of the nanotubes and their qualities. The junctions can appear either on contact of nanotube-substrate or between the nanotubes with different conductivities. In previous works the singlewalled nanotube can be either semiconducting or metallic depending on its diameter and helicity [1]. Introduction of pentagon-heptagon pair defects into the hexagonal network of a single carbon nanotube which can change the helicity of the tube and form the nanoscale metal/semiconductor or p-n type of junctions [2]. Metalto-semiconductor transition can occur while squashing the nanotubes [3], during the variation of the magnetic flux [4] or by intercalating of alkali atoms which can transform a metallic single walled carbon nanotube into a semiconductor tube with different band gaps [5]. The latter work demonstrates influence of point defects onto the carbon nanotube band structure. Similarly other type of crystal lattice defects (angular perturbations) may induce the metal-semiconductor transition [6]. Geometry of the contact nanotube substrate (nanotube (crosshatched) side contacted by the metal by van der Waals adhesion or nanotube end bonded to the metal by covalent metallic bonding) may result in different type of the nanotube-substrate contacts [7]. Similarly electronic and transport properties of the metal-semiconducting carbon nanotubes interfaces are the functions of the nanotube length and influence the parameters of the Schottky barrier formation at the interface [8].

Scanning tunneling microscopy (STM) since its introduction [9] has proved to be a functional tool for carbon molecules characterization. STM studies on samples with dif- ferent conductivity and band structure revealed important features of the technique. STM images were found to be dominated rather by electronic structure effects than the sample surface geometry [10]. By studying tunneling across a thin insulator film the STM picture depends on the tunneling current which can either enter the insulator conducting band or will not depending on the voltages between the needle tip and the surface sample [11]. The tunneling microscopy was found to be sensitive rather to spatially distributed density of electronic states in the crystal lattice. E.g. for [001] oriented fcc $\mathrm{Fe}-\mathrm{Ni}$ alloy the atoms in the surface layer can be distinguished in the STM image as brighter spots comparing to darker nickel atoms [12]. The STM studies of fullerene nanocrystals, composed of only C60, only $\mathrm{C} 70$, or mixture of the both fullerenes, resulted in the low spatial resolution STM images which reveal the spatial distribution of the electronic density originating from the fullerenes molecular orbitals but not the carbon atoms [13]. The STM studies on conducting surfaces revealed the patterns resulted from dangling bonds. The surface states are experimentally detectedSTM induced light emission detected silicon dangling bonds on hydrogen-terminated $\mathrm{Si}(001)$ surfaces which has been mapped spatially and analyzed spectroscopically [14]. Experiments revealed that atoms on the $\mathrm{Au}(100)$ surface can form specific patterns including ribbon-like reconstructed domains in order to circumnavigate surface defects [15].

The goal of this article is to study metal and carbon nanotubes by means of scanning tunneling microscopy with high spatial resolution. Microscopy resolution of the STM is planned to be studied in details in order to analyze the obtained data.

\section{Equations}

Scanning tunneling microscopy allows conducting measurements with atomic spatial resolution and registering the atomic structure of studied sample by measuring the tunneling current of electrons propagating from the sample to the tip of a sharp needle. Accuracy of coordinate registering $(\Delta x, \Delta y)$ depends on the uncertainty principle for the de Broglie electrons waves and can reach numbers of a few angstroms in the experiments. At the same time the tip of the needle is located on the distance of tens nanometers from the sample surface. As a result we can use paraxial wave approximation when dependence of the wave 

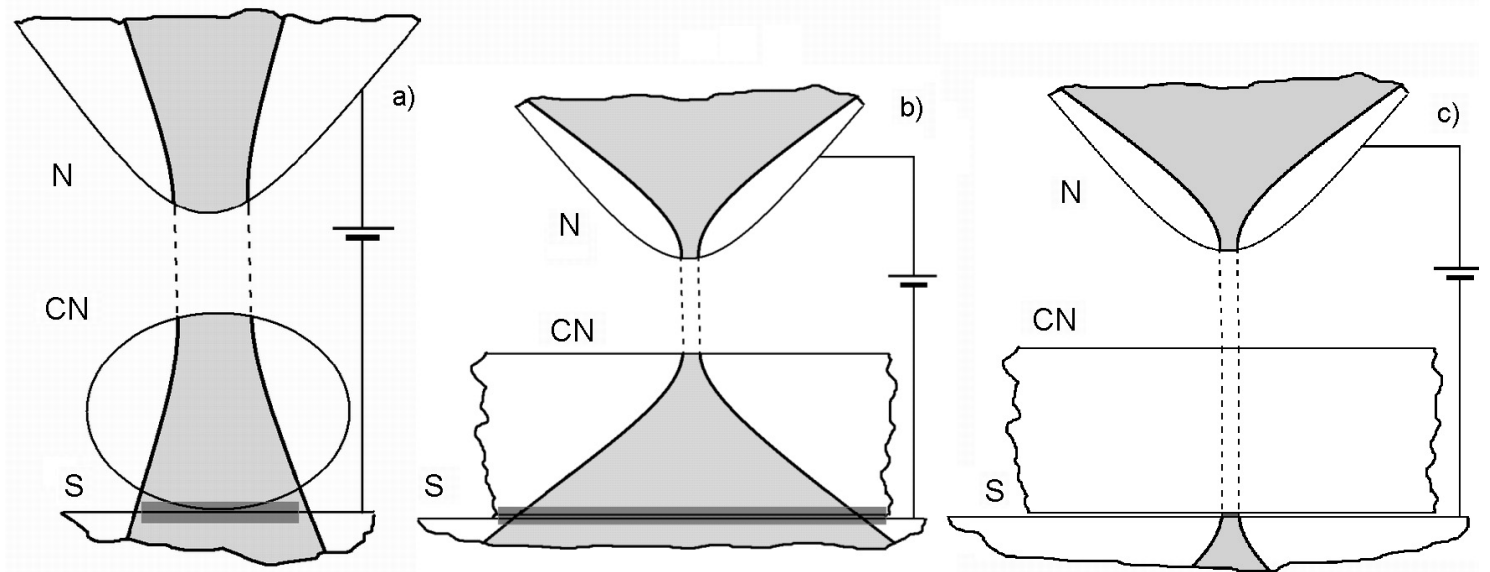

Fig. 1. Scanning tunneling microscopy of metal $(a, b)$ and semiconductor (c) nanotubes in transversal (a) and longitudinal (b) crossections. $S$ - substrate, $C N$ - carbon nanotube, $N$ - needle of the microscope. Dark-grey rectangle - electrical contact zone of nanotube-substrate. Light-grey area de Broglie wave of electron in paraxial approximation, dashed lines indicate the de Broglie wave in tunneling.

function is much less rapid than its perpendicular to the sample surface its $Z$ axis dependence.

In order to observe this we will take the time-independent Schroedinger equation for the de Broglie wave of electron in space:

$$
H \varphi(x, y, z)=E \varphi(x, y, z) .
$$

It can be derived from the wave equation for the electron wave

$$
\frac{\partial^{2} \psi(x, y, z, t)}{\partial t^{2}}+V^{2} \Delta \psi(x, y, z, t)=0
$$

in approximation $\psi(x, y, z, t)=\varphi(x, y, z) \varphi_{1}(t)$, here $\varphi_{1}(t)=\exp (i \omega t)$. Velocity $V$ and propagation vector $k$ are connected with the ratio: $k=\omega / V$. Eq. (2) solution as a point source wave in the paraxial approximation $(x, y \leq z)$ when $r=\sqrt{x^{2}+y^{2}+z^{2}} \approx$ $z\left(1+\left(x^{2}+y^{2}\right) / 2 z^{2}\right)$ (with expansion of the first order of power $\left.\left(x^{2}+y^{2}\right) / 2 z^{2}\right)$ can be written:

$$
\begin{gathered}
\varphi(x, y, z)=\exp (-i k r) / r \approx \\
\approx \frac{1}{z} \exp (-i k z) \exp \left(\frac{-i k\left(x^{2}+y^{2}\right)}{2 z}\right) .
\end{gathered}
$$

In order to remove singularity in Eq. (3) $(z=0)$ we can use Eq. (3) invariance with the respect to translation of the coordinate along $Z$ (in our case on imaginary number im):

$$
\begin{gathered}
\varphi(x, y, z) \approx \\
\approx \frac{1}{z+i m} \exp (-i k(z+i m)) \exp \left(\frac{-i k\left(x^{2}+y^{2}\right)}{2(z+i m)}\right)
\end{gathered}
$$

Splitting real and imaginary part of the wave function in Eq. (4) we can receive the following relationships:

$$
\begin{gathered}
\varphi(x, y, z) \approx \\
\approx\left(1 / \sqrt{\left.z^{2}+m^{2}\right)} \exp (i \arctan (z / m)) \exp \left(\frac{i k z\left(x^{2}+y^{2}\right)}{2\left(z^{2}+m^{2}\right)}\right)\right. \\
\exp \left(k m\left(x^{2}+y^{2}\right) / 2\left(z^{2}+m^{2}\right)\right),
\end{gathered}
$$

$\theta=\arctan (z / m)$ can be interpreted as an angle of the expansion of the de Broglie wave or the opening angle which forms the cone. The angle forms the cone which limits the part of the space where the wave is propagating. Solution (4) is the wave Gaussian amplitude profile [16] with minimum beam radius $r_{0}$ (at $z=0$ ):

$$
r_{0}=\sqrt{2 m / k} \text {. }
$$

Eq. (6) can be obtained from Eq. (5) at $z=0$. High spatial resolution $(\Delta x, \Delta y)$ of the tunneling microscopy is based on equations for propagation of vector projections:

$$
\Delta x \Delta k_{x} \geq \pi, \Delta y \Delta k_{y} \geq \pi
$$

In order to receive Eq. (7) for the solution of Eq. (5) we have to find the propagation vector projection on $z$ axis. We can do it by calculating the partial derivative of all Eq. (5) exponential functions imaginary arguments with respect to $z$ :

$$
k_{z}=k-\frac{\partial(\arctan (z / m))}{\partial z}=k-\frac{m}{m^{2}+z^{2}} .
$$




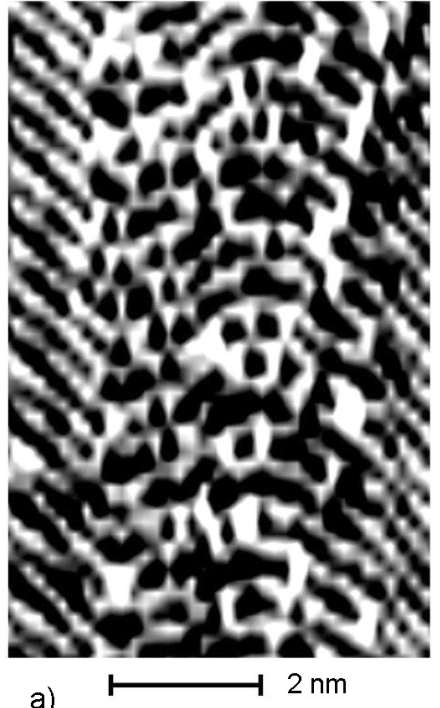

a)

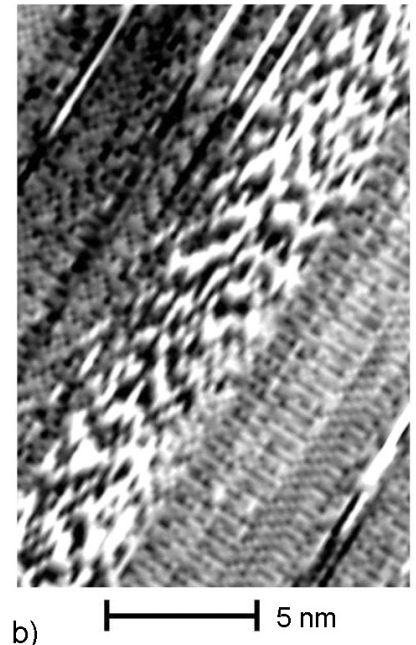

b)

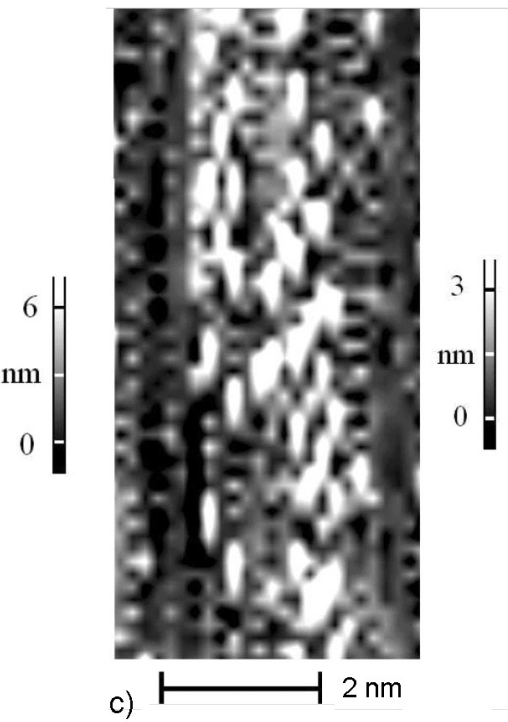

Fig. 2. Scanning tunneling microscopy of semiconductor (a) and metal (b,c) nanotube. Spatial resolution is $0.06 \mathrm{~nm}$.

Taking into account the ratio between propagation vector and propagation vector projections

$$
\left(k_{x}\right)^{2}+\left(k_{y}\right)^{2}+\left(k_{z}\right)^{2}=(k)^{2} .
$$

We can receive from Eqs. (6), (8) the relationships for the propagation vector projections on $x$ and $y$ axes at $z=0$ :

$$
k_{x} r_{0}=k_{y} r_{0}=\sqrt{2} \text {. }
$$

Practically Eq. (10) is detailed presentation of Eq. (7) $\left(r_{0} \approx \Delta x / 2\right)$ for wave functions with the Gaussian amplitude profile. Comparing Eqs. (6) and (7) we can determine the value of spatial resolution of the scanning tunneling microscopy as the double minimum radius of the Gaussian amplitude profile of the de Broglie wave $r_{0}$.

We can obtain the basic ratio for the scanning tunneling microscopy spatial resolution using the presented approach. From "raw" geometrical point of view the angle $\theta \approx l / 2 D$. $D$ is the nanotube diameter, $l-$ size of the nanotube-substrate electrical contact (horizontal dimension of dark grey rectangles in Fig. 1). Taking into account Eq. (6) we can receive the ratio for spatial resolution:

$$
2 r_{0}=4 \frac{\lambda D}{\pi l}
$$

here $\lambda$ is the de Broglie wave wavelength. Eq. (11) can be expanded for any conducting nanoobject (e.g. nanoparticle or fullerene) having $D$ diameter on the substrate with comparable electrical conductivity.

Schematic propagation of electrons in the tunneling microscope is presented in Fig. 1 for the case when carbon nanotube being scanned. We can see in the figure longitudinal and transverse sections of the carbon nanotube. From geometrical point of view the spatial confinement of nanotube-substrate electrical contact (dark grey bonds in the picture) results in smaller convergence angle $\varphi$ of the de Broglie wave and as a result taking into account Eq. (5) to large values of the spatial resolution $(\Delta x, \Delta y)$.

\section{Experimental}

For experimental confirmation the presented theoretical model we conducted scanning tunneling microscopy experiments of the carbon nanotubes deposited on a polished copper substrate. The sample was fabricated by drying a drop of water which contained the carbon nanotubes on a copper surface.

Microscope INTEGRA NT-MDT allowed conducting measurements in the scanning tunneling microscopy regime and it was used for precise surface topology study. The scanning tunneling microscopy spatial resolution reached up to 0.06 nanometer. The experiments were performed in the measurements regime with a constant tunneling current (and a constant distance of needle tip- sample surface) so we could obtain the direct surface profiles. 
We can see in Fig. 2a results of the STM measurements of semiconductor carbon nanotube (left) and the metal nanotube (right) with a few nanometers diameters. The experiments were performed with the space spatial resolution of $0.06 \mathrm{~nm}$. This value is the maximum possible spatial resolution for the semiconductor nanotube, considering the distinct difference in electrical conductivity and values for the nanotube and the substrate results in electron tunneling from the contact nanotube-substrate volume. Electrons propagate through the nanotube as the de Broglie waves through the potential barrier due to quantum tunneling. In Fig. 2 we can distinguish the semiconductor nanotube surface hexagonal structure and the substrate lattice ordered structure.

The substrate and nanotube areas have similar brightness which proves that electrons were tunneled from the electrical contact of substrate-nanotube (pixel brightness in the presented figures is proportional to $Z$ coordinate of the surface spot just beneath the needle tip). The artifacts on the edges of the nanotubes [17] are absent perhaps due to relatively small nanotube diameter. The results of the scanning tunneling microscopy for metal nanotubes with different diameters are presented in Fig. 2. We can see increased brightness of the spatial structure in the nanotube area in the figure which proves the electrons were tunneled from the upper part of the metal nanotube. The structures in the nanotube area have distinctly lower spatial resolution comparing to the Fig. 2 results. The nanotube structure in Fig. 2c is inhomogeneous that mean we can see small spots of ordered lattice in the nanotube zone. It is the result of the relatively small nanotube diameter and the result relatively narrow spatial potential barrier. The electrons are tunneled either form the upper nanotube side or from the substrate. The transversal horizontal pattern in Fig. 2a nanotubes (especially in Fig. 2 case) indicates the higher spatial resolution along the nanotube in agreement with Fig. 1 scheme.

\section{Conclusions}

The wave function with the Gaussian amplitude profile can be obtained for the time- independent Schroedinger equation for the de Broglie wave of electron in the paraxial approximation. The minimum beam radius of the wave function determines the spatial resolution of the scanning tunneling microscopy experiments. The propagation vector projections on axes are related with the minimum beam radius value forming the uncertainty principle basic ratio. The experiments on the metal and semiconductor carbon nanotubes reveal drastic difference in the scanning tunneling experiments spatial resolution. The former results show difference in the spatial resolution along and across the nanotube direction. Basic ratio for the spatial resolution for the conducting nanotube or arbitrary nanoobject on the metal substrate was derived as a result of the approach.

\section{References}

1. N.Hamada, S.I.Sawada, A.Oshiyama, Phys. Rev. Lett., 68, 1579 (1992).

2. L.Chico, T.Vincent, H.Crespi et al., Phys. Rev. Lett., 76, 971 (1996).

3. J.-Q.Lu, J.Wu, W.Duan et al., Phys.Rev. Lett., 90, 156601 (2003).

4. M.F.Lin, K.Shung, Phys. Rev.B, 51, 7592 (1995).

5. X.Yang, J.Ni, Phys. Rev.. B, 71, 165438 (2005)

6. Y.Li, U.Ravaioli, S.V.Rotkin, Phys. Rev..B, 73, 035415 (2006).

7. F.Leonard, J.Tersoff, Phys.Rev.Lett., 84, 4693 (2000).

8. Y.Xue, M.Ratner, Physical Review.B, 70, 205416 (2004).

9. G.Binning, H.Rohrer, Ch.Gerber et al., Phys. Rev. Lett., 49, 57 (1982).

10. J.Tersoff, Phys. Rev. Lett., 57, 440 (1986).

11. J.Viernow, D.Y.Petrovykh, A.Kirakosian et al., Phys. Rev. B, 59, 10356 (1999).

12. M.Ondracek, F.Maca, J.Kudrnovsky et al., Phys. Rev. B, 74, 235437 (2006).

13. F.Rossel, M.Pivetta, F.Patthey et al., Phys. Rev. B, 84, 075426 (2011).

14. C.Thirstrup, M.Sakurai, K.Stokbro et al., Phys. Rev. Lett., 82, 1241 (1999).

15. X.Gao, A.Hamelin, M.J.Weaver, Phys. Rev.B, 46, 7096 (1992).

16. H.Haus, Waves and Fields in Optoelectronics, Prentice-Hall Inc, New Jerse, (1984).

17. T.Rozouvan et al., Nano Hybrids, 8, 1 (2014). 